\title{
"UTOPÍA" COMO CONSTRUCTO SOCIOCULTURAL: ENTRE REALIDAD Y FICCIÓN
}

\author{
Paniótova Taissia S. \\ (Universidad Federal del Sur, Rostov-del-Don, Rusia)
}

\section{RESUMEN}

El artículo está dedicado al problema de la correlación entre los hechos y la ficción en la utopía social, entendida como "constructo socio-cultural", o una especie de objeto ideal cuya existencia depende de la conciencia del sujeto. La autora se pregunta: ¿qué es precisamente lo que determina la conciencia misma del sujeto, la forma y el contenido del objeto ideal? Para responder a esta pregunta, la autora toma en consideración el conjunto de circunstancias vinculadas con la escritura de la Utopía, y realiza la reconstrucción sistemática de los contextos en los que se encontraba Tomás Moro. Tal enfoque permite descubrir la dialéctica entre lo real y lo fantástico, lo verdadero y lo imaginario, y mostrar el papel de la invención en la Utopía. De una parte, la alusión a hechos y documentos da a la invención apariencia de verosimilitud. Por otra parte, la invención permite expresar los sueños más secretos y audaces como verdad, realizados en la perspectiva histórica. En el artículo se muestra que es propio de la Utopía el entrelazamiento extravagante de la invención y el hecho, algo que se convertiría más tarde en una de las características principales del género utópico. En gran parte, esto fue predeterminado por la "inspiración americana" (P. Borges ) propia de la época del Renacimiento y de la Era de los Descubrimientos.

PALABRAS CLAVE utopía, Tomás Moro, real, imaginario, Nuevo Mundo

\section{"UTOPIA" AS A SOCIOCULTURAL CONSTRUCT: BETWEEN FACT AND FICTION}

\begin{abstract}
The article explores the problem of fact and fiction correlation in the construction of social utopia. The author of the article understands "sociocultural construct" as an ideal object whose existence depends on the subject's consciousness. So the question arises: what exactly determines the subject's consciousness, the form and content of the ideal objects produced by them? To answer this question the author takes into account the whole set of circumstances connected with the creation of
\end{abstract}


"Utopia". The author also considers all the contexts in which Thomas More lived. This approach allows to reveal the dialectics of the real and the fantastic, the true and the imaginary, and to show the role of fiction in the work. On the one hand, reference to real facts and documents gives fiction the appearance of plausibility. On the other hand, fiction allows us to formulate the most cherished and boldest dreams as truths that are possible in the historical perspective. The article shows that fanciful interlacing of fantasy and facts inherent to "Utopia" later turned into one of the main characteristics of the utopian genre. This was largely predetermined by the "American inspiration" (P. Borges) typical of the Renaissance and the Age of Discovery.

KEYWORDS: utopia, Thomas More, real, imaginary, New World

En 2016 se han cumplido 500 años desde la publicación de "Utopía" de Tomás Moro. Este pequeño libro no sólo constituyó el nacimiento de un nuevo género literario, sino que también abrió el camino a una nueva forma de pensar el futuro, relacionada con la construcción de una realidad alternativa imaginaria. No es exagerado decir que sin "Utopía" el desarrollo del pensamiento social y, tal vez, el de la misma historia, habría sido distinto. Es por eso por lo que el aniversario de Utopía ha sido conmemorado ampliamente en todo el mundo.

Después de su primera publicación, el "Libro del Estado ideal de una república y de la nueva isla de Utopía" fue traducido a diferentes idiomas y fue objeto de múltiples reflexiones y evaluaciones. El continuo interés por la obra de Tomás Moro se debe no sólo a la complejidad y la diversidad de capas que esconde lo que se muestra como un sencillo y simple relato de viajes; y no sólo a los cambios históricos, sociales y culturales que ha producido en el transcurso de 500 años, sino también a la personalidad de su autor. En efecto, Tomás Moro fue uno de los intelectuales representativos de la cultura renacentista, en el cruce entre la Edad Media y la Edad Moderna; en él se combinan el ascetismo y el hedonismo, el racionalismo y el misticismo; fue al mismo tiempo revolucionario, reformista y tradicionalista. Algunos autores lo han considerado el precursor del colonialismo británico, mientras que en la Unión Soviética se lo tenía en estima como el predecesor del comunismo científico, a tal punto que su nombre quedó grabado en el "Monumento a los ideólogos y luchadores por la liberación de los trabajadores". Y otro dato no menor es que en fecha tan reciente como 1935 fue canonizado por el Vaticano.

$\mathrm{Al}$ igual que pasa con su autor, Utopía no permite una interpretación única e inequívoca: es, al mismo tiempo, una novela de viaje, una forma de crítica social, un tratado político y la fantasía de un lugar con un orden social mejor. Se puede estar de 
acuerdo con Raúl Morodo respecto a que «Moro crea también, metodológicamente, un novum instrumentum, con el cual la política pueda ser observada con un nuevo prisma, es decir, conectando realidad y ficción».

De aquí sigue que la esencia del novum instrumentum consiste en una síntesis entre la fantasía y la realidad, que posteriormente se convertirá en una de las características básicas de los constructos utópicos. En el campo de la epistemología, bajo el término "constructo" se entiende un objeto ideal cuya existencia depende de la conciencia del sujeto, a diferencia de un objeto real, cuya existencia es independiente de la mente de cualquier sujeto. Sin embargo, es razonable plantear la siguiente pregunta: ¿qué factores y de qué manera influyen en el pensamiento del sujeto y en el nacimiento de los objetos ideales? Para entender la esencia de Utopía como constructo sociocultural es importante tener en cuenta toda una serie de circunstancias relacionadas con su proceso de escritura; esto es: el contexto espacio-temporal en el cual se escribió, así como el círculo íntimo del autor y las fuentes utilizadas.

Entre los personajes del libro figuran personas reales con las cuales Moro había dialogado en Flandes y en distintas etapas de su vida. Entre ellos, Pedro Egideo, a quien se dirige el prólogo; Juan Clemente, secretario de Moro; John Morton, cardenal, arzobispo y Lord canciller del reino en la época de Enrique VII; Erasmo de Rotterdam, J. Budsleiden, W. Bude, I. Frobenius, A. Vespucio, etc. Algunos de ellos son participantes directos de los acontecimientos descritos, otros figuran como autores de cartas de recomendación, de características de la obra y del autor, y de los poemas que acompañan a Utopía. La paradoja consiste en que muchos de estos textos mienten, en tanto que dan recomendaciones a personas y caracterizan positivamente lugares que no existen. No obstante, las mentiras son proclamadas por personas muy respetadas, dándole así al relato un aspecto de verdad aparente. La descripción de la isla de Utopía es tan auténtica que incluso ha llevado a algunos autores a afirmar que el libro no es ficción, sino el relato de lo que Hitlodeo presenció durante su viaje a Perú. Cabe destacar que Moro no podría saber nada sobre el imperio de los Incas, ya que el descubrimiento de Perú fue en una época más tardía (1532). Por su parte, Silva Herzog y Martínez Estrada han investigado la posible relación histórica de Utopía en las descripciones de la isla $\mathrm{Cuba}^{2}$.

Los argumentos de estos autores, sin embargo, no resisten la crítica. En primer lugar, el nombre del país lo dice todo: Utopía, es decir, algo inexistente (Nusquama - "no existente en ninguna parte"); otros topónimos inventados por Moro: el río Anidro (sin agua), la ciudad de Amaurota (oculto en la niebla), Amadeus (el gobernador sin pueblo),

${ }^{1}$ Raúl Morodo Leoncio, El laberinto utópico de Tomás Moro (Madrid: Real Academia de Ciencias Morales y Políticas, 2015) http://www.racmyp.es/R/racmyp/docs/anales/A92/A92-1.pdf (consultado el 7 de abril de 2017).

${ }^{2}$ Jesús Silva Herzog. "Las Utopías del Renacimiento", en Antología: conferencias, ensayos y discursos (México: UNAM, 1981), 52-79. Ezequiel Martínez Estrada, "El nuevo mundo, la isla de Utopía y la isla de Cuba", Cuadernos americanos 2 (1963): 89-122. 
alaopolitas (ciudadanos sin estado) y otros. En segundo lugar, el viajero se llama Hitlodeo, su nombre proviene de dos palabras griegas: hitlos y dayos, que significa "charlatán". Por último, no se pueden dejar de lado las palabras del autor, que se repiten a lo largo del texto, por ejemplo: «También diré que existen en la república de los utopianos muchas cosas que quisiera ver impuestas en nuestras ciudades. Pero que no espero lo sean» ${ }^{3}$.

Ahora bien, donde Moro muestra inclinación por el realismo y los hechos es en la descripción de la realidad europea. Moro realiza una especie de diagnóstico en el cual revela una variedad de males sociales y sus causas. Entre ellos se encuentran el despojo de las tierras y el empobrecimiento del campesinado inglés como resultado de la conversión de tierras en pastizales para las ovejas; en relación con esto, el aumento del robo, el pillaje y la presencia de vagabundos; las injustas medidas tomadas por el Estado contra el vagabundeo, entre las cuales se incluía hasta la pena de muerte; la corrupción de los jueces; la gran cantidad de nobles que vivían a costa del trabajo de otros; la presencia de ejércitos enormes que vaciaban las arcas; las interminables guerras, fruto de la ambición territorial y política de los estados europeos, etc. En principio, muchos de los eventos y los estados sobre los que habla Moro son reales y fácilmente reconocibles, además de los que él mismo frecuentemente menciona (la Batalla de Cornualles, o la guerra con Francia, entre otros). Sin embargo, en la narrativa aparentemente realista se tejen hilos fantásticos. Por ejemplo, Hythlodeo habla sobre un pueblo que supuestamente vive en Persia:

Es lo que pude observar en uno de mis viajes a Persia, entre unas tribus conocidas con el nombre de polileritas. Se trata de un pueblo numeroso y bien gobernado. A excepción de un pequeño tributo anual que pagan al rey de Persia, gozan de plena libertad y se gobiernan por sus propias leyes...Viven con comodidad, pero sin lujo, preocupados más de la felicidad que de la nobleza o el nombre, pues pasan desapercibidos de todo el mundo, a no ser de sus vecinos más inmediatos. ${ }^{4}$

Vale la pena indicar, que el nombre de este pueblo - polileritas- esta formado de dos palabras griegas que significan "mucho" y "charlatanería".

Podemos preguntar: ¿De qué documentos podía disponer Moro para la construcción de su mundo ideal? ¿Cuánto había de fantasía y de realidad en estas fuentes? Como indica Pedro Borges, Moro podía obtener información sobre el Nuevo Mundo, donde el ubicó la isla Utopía, de diferentes textos impresos así como de las conversaciones que tenían lugar en la corte real y de los rumores difundidos en la sociedad. Entre todos estos, es necesario distinguir:

\footnotetext{
3 Tomás $\quad$ Moro, $\quad$ Utopía, 78

http://ocw.uca.es/pluginfile.php/1497/mod resource/content/1/Utopia Tomas Moro.pdf (consultado el 7 de abril de 2017).

${ }^{4}$ Ibídem, 13. 
1. La primera carta de Colón, publicada en Amberes en el verano de 1493, que contenía información importante sobre Nuevo Mundo;

2. la inserción por Martin Waldseemüller de la ultima carta de Americo Vespuccio que recoge los cuatro viajes en su Cosmographias introductio, cum quibusdam geometriae ac asronomiae principiis, insuper quatuor Americi Vespucci navigationes, editada en 1507;

3. Diferentes tipos de datos proveniente de las Indias Occidentales durante su servicio al rey Enrique VIII, que por aquel entonces (1509) había contraído matrimonio con Catalina de Aragón.

4. Los escritos de Pedro Mártir de Angleria, historiador real, que contaba con mucha información sobre el Nuevo Mundo de primera mano, es decir, de parte de navegantes, conquistadores, misioneros, etc.

Además, Moro podía acceder directamente a algunas "curiosidades" del Nuevo Mundo, por ejemplo, a indios traídos por los sacerdotes que habían estado en América, vestidos con pieles y comiendo carne cruda cerca de Abadía de Westminster ${ }^{5}$.

La información que llegaba del Nuevo Mundo era muy contradictoria. Por un lado, esta información consistía en descripciones entusiastas de aborígenes buenos, habilidosos y hospitalarios que no conocían en concepto de "lo mío" y "lo tuyo", y que no separaban las tierras mediante cercas. Es decir, a través de esta información dada por los testigos contamos con una visión "optimista" sobre la vida de los indios del Nuevo Mundo. Pero, por otro lado, en los mismos textos encontramos descripciones de gigantes de dos metros, de personas con hocico y colas de perro, de personas con un solo ojo en la frente, etc. En los textos de los viajeros y cronistas hay también descripciones de la Edad de Oro, que de forma milagrosa se habría conservado en el Nuevo Mundo, con los rasgos de abundancia y orden natural.

Citaremos algunos párrafos de las fuentes principales. En primer lugar, la carta de Cristóbal Colón:

Las tierras... todas hermosísimas, de mil fechuras, y todas andables, y llenas de árboles de mil maneras y altas, y parece que llegan al cielo"; "la gente de esta isla y de todas las otras que he hallado y he habido noticia, andan todos desnudos, hombres y mujeres, así como sus madres los paren ..., ellos no tienen hierro, ni acero, ni armas, ni son para ello, no porque no sea gente bien dispuesta y de hermosa estatura, salvo que son muy temeroso a maravilla..., y muestran tanto amor que darían los corazones"..., " procuren de ayuntar y nos dar de las cosas que tienen en abundancia, que nos son necesarias. Y no conocían ninguna seta ni idolatría salvo que todos creen que las fuerzas y el bien es en el cielo, y creían muy firme que yo con estos navíos y gente venía del cielo", y tienen "muy sutil ingenio"; "no he podido entender si tienen

\footnotetext{
${ }^{5}$ Pedro Borges Morán, "Inspiración americana de la Utopía de Tomás Moro", Mar Océana: revista del bumanismo español e iberoamericano 26 (1995): 91-111, 100-104.
} 
bienes propios; que me pareció ver que aquello que uno tenía todos hacían parte, en especial de las cosas comederas ${ }^{6}$.

Las características del Nuevo Mundo aparecen también en las cartas de Americo Vespuccio:

En aquellos países hemos encontrado tal multitud de gente que nadie podría enumerarla... y todos de uno y otro sexo van desnudos, no se cubren ninguna parte del cuerpo" , "no tienen paños de lana ni de lino ni aún de bombasí porque nada de ello necesitan; ni tampoco tienen bienes propios, pero todas las cosas son comunes. Viven juntos sin rey, sin autoridad y cada uno es señor de sí mismo" Además no tienen ninguna iglesia, ni tienen ninguna ley ni siquiera son idólatras... Viven según la naturaleza, y pueden llamarse más justamente epicúreos que estoicos?

Así mismo, Pedro Mártir de Angleria, basándose en la obra y las entrevistas con Colón en su Primera Década, presenta la descripción de los costumbres de aborígenes que eran

más felices que aquellos [que conoció Eneas], con tal que reciban la religion; porque viviendo en la edad de oro, desnudos, sin pesos ni medidas, sin el mortífero dinero, sin leyes, sin jueces calumniosos, sin libros, contentandose con la naturaleza, viven sin solicitud ninguna acerca del porvenir...»; añadiendo que «tienen ellos por cierto que la tierra, como el sol y el agua es común y que no debe haber entre ellos mío y tuyo, semillas de todos los males... Para ellos es la edad de oro. No cierran sus heredades ni con fosos, ni con paredes, ni con setos...; de su natural veneran al que es recto, tienen por malo y perverso al que se complace en hacer injuria a cualquiera ${ }^{8}$.

Los escritores contemporáneos han hecho diferentes valoraciones sobre el grado de fiabilidad de estas importantísimas fuentes, así como también sobre la posibilidad de su empleo por Tomás Moro. Demetrio Ramos, que acepta el importante papel de la primera carta de Colón en la historiografía de América, manifestó su duda en que la carta publicada en 1493 pudiera ejercer una influencia sustancial sobre Moro cuando éste escribió su Utopía, veinte años más tarde. Además Ramos considera que el punto de vista del protagonista puede introducir errores en el análisis histórico:

\footnotetext{
${ }^{6}$ Cristóbal Colón. "La Carta de Cristóbal Colón anunciando el descubrimiento del Nuevo Mundo", en Selected Documents Illustrating the four Voyages of Columbus, ed. Lionel Cecil Jane (Londres: The Hakluyt Society, 1930), I, 2-19 http://www.ensayistas.org/antologia/XV/colon/ (consultado el 7 de abril de 2017).

7 Americo Vespucio. "El Nuevo Mundo (¿1503?). Naturaleza y costumbres de aquella gente", en Historia real y fantástica del Nuevo Mundo (Caracas: Biblioteca Ayacucho, 1992), 27-29, 27-28.

${ }^{8}$ Pedro Mártir de Angleria, Décadas del Nuevo Mundo. Ed. Ramón Alba (Madrid: Polifemo, 1989), 145-146; 201-202.
} 
Es evidente que los escritos de Cristóbal Colon, y en especial su Diario, ocupan un lugar principalísimo, como piezas inestimables para el conocimiento de los hechos de la época de los descubrimientos. Mas son como los documentos o fuentes, repletos de contenido histórico, pero no historia en si mismos, pues ni son escritos públicos ni se redactaron como crónica, para asumir unos hechos reflexivamente, que es lo que requiere el relato historial, que necesita ser escrito desde fuera del protagonista 9 .

Para Demetrio Ramos la fuente más probable de información fueron las Décadas de Pedro Mártir de Angleria, publicadas en 1511 en Sevilla. Con la ayuda de Catalina de Aragón éstas pudieron llegar a manos de Tomás Moro, que se encontraba en la corte real en aquel periodo.

Al mismo tiempo, Pedro Borges afirma que una indudable influencia en el autor de la Utopía vino de las cartas de Américo Vespucio, las cuales eran muy leídas en Europa durante el periodo en que Moro estuvo en Amberes en misión diplomática; tanto más cuanto que él cita precisamente a Vespucio. Borges señala que desde el año 1507, cuando la ultima carta de Vespucio que contenía la descripción de sus cuatro viajes fue traducida al latín por Martín Waldseemüller e incluida en sus Cosmographias introductio, cum quibusdam geometriae ac astronomiae principiis, insuper quatuor Americi Vespucci navigationes, esta obra fue publicada más de siete veces. Concluye diciendo: «Por lo mismo, la obra aludida por Moro y que andaba "en manos de todos" no puede ser otra que esta Cosmographiae introductio, en la que se insertan las quatuor navigationes o cuatro viajes vespucianos ${ }^{10}$.

Sin entrar en discusión, afirmamos que en todos los textos antes mencionados están entrelazados hechos reales con rumores, exactas características antropológicas con imágenes de monstruos. Es importante aclarar, qué era lo que le interesaba a Tomás Moro en estos textos y que clase de información de las fuentes propuestas interpretaba y utilizaba.

¿Qué tipo de información podía despertar el interés para Moro? Encontramos la respuesta a esta pregunta en el mismo texto de la Utopía:

Por supuesto que en nuestra conversación no aparecieron para nada los monstruos que ya han perdido actualidad. Escilas, Celenos feroces y Lestrigones devoradores de pueblos, y otras arpías de la misma especie se pueden encontrar en cualquier sitio. Lo difícil es dar con hombres que están sana y sabiamente gobernados ${ }^{11}$.

\footnotetext{
${ }^{9}$ Demetrio Ramos Pérez, Variaciones ideológicas en torno al Descubrimiento de América. Pedro Mártir de Angleria y su mentalidad (Valladolid: Casa-Museo de Colon \& Seminario Americanista, 1981-1982), 9.

${ }^{10}$ Borges, "Inspiración americana", 98.

${ }^{11}$ Moro, Utopía, 5.
} 
¿Puede ser que Moro haya detectado este tipo de estado en el Nuevo Mundo? Es difícil de creer, ya que en el momento de la redacción de Utopía todavía no se habían descubierto las civilizaciones americanas y no tenía forma de disponer de información sobre las "excelentemente gobernadas republicas" narradas por Hitlodeo. Ninguno de los autores o de los viajeros escribió acerca del "estado óptimo del Estado" en el Nuevo Mundo. A nuestro parecer, en este contexto, desempeñó un rol principal el fragmento en el cual Moro, a través de la voz de Hitlodeo, cuenta la historia de un sabio navegante de nombre Utopo, que hace más de mil años cayó en la isla como resultado de un naufragio y la conquistó. «Fue Utopo quien se apoderó de la isla y le dio su nombre, pues anteriormente se llamaba Abraxa. Llevó a este pueblo tan inculto y salvaje a ese grado de civilización y cultura que le pone por encima de casi todos los demás pueblos» ${ }^{12}$.

Si seguimos la lógica del lord canciller podemos llegar a la siguiente conclusión: el hombre natural puede salir del estado de salvajismo, aprender conocimientos y habilidades necesarias y convertirse en un ser civilizado, capaz de crear la "república óptima" y superar a todos pueblos sólo bajo la dirección de un gobernante sabio y autoritario llegado del Viejo Mundo, teniendo en cuenta que entre los compañeros de Utopo se encontraban egipcios y griegos. Y aquí, como en muchos otros casos, la ficción (La República de Platón) se apoya en hechos reales -órdenes indígenas-, recurso hábilmente utilizado para justificar la autenticidad de la ficción. Por otro lado, es la misma ficción la que transmite el sentido fundamental a la obra, la idea principal y la intención del autor; justamente la ficción tiene la oportunidad de convertirse en realidad con una perspectiva histórica.

A modo de síntesis, podemos destacar algunos rasgos del constructo "utopia" inventado por Moro: la combinación del hecho real con la ficción; la imaginación artística y la racionalidad filosófica; la crítica social sobre realidad existente y el proyecto de una sociedad ideal, la ironía y la seriedad, etc. De importancia fundamental para la creación de este constructo fue la información proveniente de diversas fuentes en las que se describía un Nuevo Mundo aún desconocido para los europeos y percibido como opuesto a la forma de vida del Viejo Mundo. Sin embargo, no se puede decir que la Utopía de Tomás Moro sea un reflejo fiel de la realidad del Nuevo Mundo de aquel entonces. Moro analizaba críticamente la información obtenida, la comparaba con textos clásicos y no idealizaba la barbarie indígena. Hay razones para creer que él consideraba a América como un fragmento conservado del pasado histórico de la humanidad y relacionaba la posibilidad de un ulterior desarrollo del continente con la incorporación de sus pueblos a los valores culturales universales.

\footnotetext{
12 Ibídem, 26. 


\section{BIBLIOGRAFÍA}

Borges Morán, Pedro, "Inspiración americana de la Utopía de Tomás Moro", Mar Océana: revista del humanismo español e iberoamericano 26 (1995): 91-111.

Colón, Cristóbal. "La Carta de Cristóbal Colón anunciando el descubrimiento del Nuevo Mundo", en Selected Documents Illustrating the four Voyages of Columbus, ed. Lionel Cecil Jane (Londres: The Hakluyt Society, 1930), I, 2-19 http://www.ensayistas.org/antologia/XV/colon/ (consultado el 7 de abril de 2017).

Martínez Estrada, Ezequiel, "El nuevo mundo, la isla de Utopía y la isla de Cuba", Cuadernos americanos 2 (1963): 89-122.

Mártir de Angleria, Pedro, Décadas del Nuevo Mundo. Ed. Ramón Alba (Madrid: Polifemo, 1989).

Morodo Leoncio, Raúl, El laberinto utópico de Tomás Moro (Madrid: Real Academia de Ciencias Morales y Políticas, 2015) http://www.racmyp.es/R/racmyp/docs/anales/A92/A92-1.pdf (consultado el 7 de abril de 2017).

Moro,

Tomás,

Utopía

http://ocw.uca.es/pluginfile.php/1497/mod resource/content/1/Utopia T omas Moro.pdf (consultado el 7 de abril de 2017).

Ramos Pérez, Demetrio, Variaciones ideológicas en torno al Descubrimiento de América. Pedro Mártir de Angleria y su mentalidad (Valladolid: Casa-Museo de Colon \& Seminario Americanista, 1981-1982).

Silva Herzog, Jesús. "Las Utopías del Renacimiento", en Antología: conferencias, ensayos y discursos (México: UNAM, 1981), 52-79.

Vespucio, Americo. "El Nuevo Mundo (¿1503?). Naturaleza y costumbres de aquella gente", en Historia real y fantástica del Nuevo Mundo (Caracas: Biblioteca Ayacucho, 1992), 27-29.

Recibido: 10 de abril de 2017

Aprobado: 5 de octubre de 2017 